\title{
Benefits of Collaborative Finance Research in Business Schools
}

\author{
Robert Kao, PhD \\ Assistant Professor of Finance, School of Business \\ Park University
}

Collaboration in business research provides outcomes and results that are more efficient than those due to individual efforts. The integration of diverse environments and disciplines often generates creative ideas. Collaboration increases the quality of research and effectiveness of discoveries, and promotes the dissemination of knowledge. Cases of collaborative finance research in the business schools are illustrated in this study. The findings include many significant benefits in knowledge stimulation, education advancement, community connections, and other rewarding results. Benefits of collaborative research outweigh the challenges and contribute to faculty development, student education, and advancements in the field of business.

\section{Introduction}

"Although business students account for approximately 22 percent of undergraduate degrees in the U.S., business is one discipline that has been largely absent from the discussion about undergraduate research" (Bartkus 2010, p.5). Professor Bartkus has introduced the Research Group model to encourage greater involvement of faculty and students. Since then, the Research Group in the Jon M. Huntsman School of Business at Utah State University has continued to evolve and provide benefits to both students and faculty members.

Business research requires support in many forms, i.e. expertise in the disciplines, data resources, the collection and analysis of data, documentation, and review process. When compared to individual efforts, collaboration provides more efficient outcomes and results. Creative ideas stem from the integration of diverse environments and disciplines. Collaborative research efforts can also reduce the risk of there being misjudgments, adverse outcomes, unnecessary wastes, and worn-out ideas. Collaboration increases the quality of research and effectiveness of discoveries, and promotes the dissemination of knowledge.

Academic and research collaboration has the advantages of creating a new type of working culture that supports teamwork and partnerships, and encourages innovations and advancement of knowledge.

Collaborative research activities are essential to the professional development of faculty and the education of students in the business area. Nevertheless, the resources and culture that support scholarship vary greatly from school to school. Faculty and students now have higher and more noticeable expectations of engaging in such activities. The demand for sharing solutions to challenges, identifying opportunities, and strengthening the scholarly environment is growing significantly in many schools of business. Such research activities depend on there being institutional support, available funds, and eligible expertise. In addition, collaborative research can assist faculty development and fulfill their training requirements. A solid research-to-education program would emerge, implement, and evaluate creative and innovative educational materials for the advancement in business areas.

\section{Review of Collaborative Business Research}

A primary purpose of the early research collaboration in many U.S. universities was to respond to the demand from the local economies. Many of such 
research collaborations were initiated before World War II in the area of engineering, i.e., "start-up companies based on university research, universityindustry-government research centers, faculty consulting, and licensing of university-generated inventions" (National Academy of Sciences, 1999, p.6). Later, the Bayh-Dole Act or the Patent and Trademark Laws Amendments of 1980 (PL 96517) enacted and abridged the federal policy on patenting and licensing of the publicly funded research by nonprofit institutions.

Although business schools generally include a three-fold mission on education, research, and service, some institutions have a primarily educational focus and conduct little research. Collaboration in these cases usually refers to the relationship between collaborators who are involved with the project as coauthors of the resulting publications. They attend meetings, participate in conference calls, and are intensively involved in two-way collegial communication with other collaborators. Fishbaugh (1997) has defined this collaboration as a formal body established by two or more autonomous partners, none of whom is under contract to another but whose aim is to attain substantive or symbolic goals that no partner could achieve independently.

Academic and research collaboration has the advantages of creating a new type of working culture that supports teamwork and partnerships, and encourages innovations and advancement of knowledge. Partnerships usually include:

Students, faculty, and community members who collaboratively engage in research with the purpose of solving various pressing community problems or reflecting some social changes. Participants are those who involved in educating themselves for social change or may be used by academics in conjunction with key social institutions (Strand et. al., 2003, p.3).

In terms of personal growth, Lopatto (2006) has pointed out that the participation in undergraduate research contributes to personal growth in students' selfconfidence, tolerance for obstacles, interest in their discipline, and sense of accomplishment.

Katz and Martin (1995) explained in their paper about why collaboration is very difficult to define:

Partly, this is because the notion of a research 'collaboration' is largely a matter of social convention among scientists. Mostly, there was little consensus on where other as well as less formal links between scientists 'end' and collaboration 'begins'. What some might deem collaboration, others may merely regard as a loose grouping or a set of informal links (p.26).

They concluded that collaboration constituted varies across disciplines, schools, industries, and regions, and that it probably changes over a period of time.

Subsequently, the study by Loan-Clarke and Preston (2002) showed collaboration between a Business School and a National Health Service Trust in the UK. They indicated various tensions exist, including "theory versus practice; generalizability versus specificity of knowledge; research rigor versus research relevance; long(er) versus short timescales of work; 'outsider' and 'insider' perspectives" (p.169). They suggested that section pressures could lead to differing priorities for the two institutions involved in the collaboration.

Furthermore, Adams et al. (2006) emphasized that "interdisciplinary research would better reflect the realities of modern businesses, where people from different specialties collaborate with each other, rather than compete" (p.32). They emphasized that crossing disciplinary boundaries for research projects were not to the benefit of academic journals only. It also made professors more valuable to their schools, and helped them provide a richer and more important interdisciplinary approach to research. It would "provide more creative, thorough, and readily applicable solutions for the increasingly complex problems in real-world business" (p.34).

More recently, Bartkus, Mills, and Olsen (2010) have proposed the Research Group framework as an approach to help systemize the process and 
thereby facilitate higher quality undergraduate research experiences for students. They motivated their students to have their research presented at such undergraduate research venues as Research Day at the State Capital and the National Conference on Undergraduate Research. The papers on whose research many students had collaborated with faculty had led to publications in scholarly journals and conference proceedings. Others had presented their research reports to the collaborative companies.

\section{Influences of Collaborative Business Research}

For researchers, the major benefit of working together is in achieving the common goal of producing new systematic knowledge. Generally, if researchers collaborate to advance a specific area of knowledge, they begin with exchanging ideas on hypotheses, experiments, measurements, and documentation of the discovered results. Further, they develop theoretical models and perform the valid testing procedures. Members of a research group will not only communicate among themselves but will also seek advice and help from others to achieve their goal.

One important factor in collaboration is the mounting costs of research and the shrinking state budget for higher education. In many areas, costs have increased substantially merely for an introduction of basic research. As a result, it has often become impossible for funding agencies to provide the necessary funds to all the research groups working in an area. Resources have had to be pooled at different levels, such as district, regional, national, or even global. Consequently, many researchers have tried to reduce the constantly rising costs by collaborating more closely.

The breakthrough of advanced communication in Internet technology has made collaboration among researchers easier than ever. Furthermore, the development of such a technology has often greatly reduced the time needed to travel or to exchange the ideas. Subsequently, informal links between institutions and networks have become very common for collaborating researchers in recent years.

Another aspect of collaboration is the growing need for specialization within certain areas that require complex research procedures. In order to carry out research, one may need to bring together experts in such tasks as gathering and analyzing data, relating the results to theory, writing up the results, presenting the findings, applying research grants, liaising with the management, managing the collaboration, and adding other administrative responsibilities. Therefore, a team or collaborative effort is required to accomplish or resolve the complex tasks and problems in business research nowadays.

\section{Cases of Collaborative Business Research}

\section{Collaboration between Faculty and Student}

The first such case involved collaboration between faculty and student in the University's Honor Program. The university degree with honors program features faculty highly motivated to work with academically exceptional students. The focus of the program during the final two academic years allows students to engage in a self-designed exploration of a topic about which the student feels passionately. Students interact with a faculty mentor who guides their exploration of the research subject. Honors Program students receive one-on-one attention designed to help them realize goals that include contributions to local and global communities, internships, study abroad, graduate school, and careers. Students can also participate in collaborative research to develop their leadership potential.

I had an opportunity to serve as a mentor for a senior business student who was in the Honors Program. The goal of this study was to access the financial knowledge of 
university students, and prepare recommendations for creating a nonprofit organization that would serve as an instrument to promote financial literacy among students. This proposed organization is to increase financial awareness among college students through the use of literature, educational seminars, and other awareness events.

The project began by taking a selection instrument survey of all student participants to determine their eligibility. A self-assessment survey and a financial literacy quiz were conducted to assess their financial knowledge and their interest in a financial literacy of nonprofit organization. The results of the study showed students' interests in a financial literacy of nonprofit organization. Also, it suggested that the use of appropriate pedagogical methods and marketing tools is the essential to form the organization. The results concluded that a nonprofit organization specializing in financial literacy along with other pedagogical means would meet the need and improve the financial literacy level of college students in the short-run. It would also help to prevent financial crises in the future. Through this faculty and student collaborative research project, the student completed the survey and study as well as presented in the conference. The student received the People to People International 2011 University Chapter Leadership Award and was recognized at the Board of Trustees meeting in Brussels, Belgium.

\section{Collaboration between Faculty}

The complexity and magnitude of business research has increasingly required more varieties of knowledge, skills, and technologies. Often, there is no one involved who has the ability and skills to meet the research requirements alone. Although someone who can handle and resolve a particular problem might be available, this arrangement can be very time consuming. When a group of researchers collaborate on a particular project, their various trainings and skills can help to accomplish the tasks more thoroughly and efficiently.

The second case of faculty collaboration in business research involved faculty partners who taught at private and state business schools and collaborated on research in the finance area. The state school had funded databases, and its faculty partner provided the data analysis. The private school's faculty partner collaborated by providing the results of analysis and writing the research manuscript for their study analyzing the financial ratio of major US companies. Both collaborating business faculty members shared their knowledge and skills in this project. One undergraduate student in the business school was also involved in this study, and worked on the data preparation. The cross-stimulation of ideas and dissemination of results included data extraction, hypothesis testing, theoretical modeling, manuscript preparations, conference presentations, and publications. The student also had an opportunity to present the paper at the business conference. Furthermore, faculty partners in the business schools incorporated the collaborative research findings in their teachings.

The benefit from this collaboration and team work is the intellectual companionship created. The entire collaborative process of this research project may be divided into the following phases: construction, operation, assessment, documentation, and dissemination. Collaboration can thus ensure effective use of partners' talents and save time by transferring knowledge or skills.

\section{Collaboration between Faculty, Student, and Institution}

The third case involved research collaboration between the business school and an outside nonprofit organization. One business student was also involved in this project, and enrolled this research as an Independent Study credit. The scope of the project included analyzing the organization's current financial statement, reconciling capital inflows and outflows with different channels, and implementing the financial revenue statements for different venues. The results benefited all the 
collaborative partners: The nonprofit organization would benefit from implementing the efficient and automated financial reporting system for their different business venues. The student received degree credit and gained experience from working with the outside company. The faculty also benefited from contacting the outside business partner and helping student throughout the project.

This type of research collaboration generates cross-stimulation of viewpoints that may in turn create new approaches and perspectives that the company, with its limited resources, would not otherwise be able to achieve. The improved financial recording system in the area of business operations would increase the effectiveness and clarity of financial reports for the company's ticket sales and revenue reports in several sales venues.

Such collaboration could also widen the researchers' network in their specific communities, institutions, or regionals and beyond. By using their network of contacts, collaborators can disseminate their findings in numerous formats, including community involvement, seminar demonstration, conference presentation, or simply informational discussions. Together, collaborators are likely to achieve a greater degree of visibility for their research findings. The outcomes are therefore likely to have greater influence in related fields.

\section{Summary and Conclusion}

Efforts to collaborate in business research provide many beneficial outcomes and help to integrate diverse disciplines among faculty and students. Besides reducing the risk of misjudgments, adverse outcomes, unnecessary wastes, and worn-out ideas, collaboration increases the quality of research and effectiveness of discoveries, and promotes dissemination of knowledge in the field of business. Such collaborative activities are essential to the professional development of faculty and the education of students. Inevitably, the resources and culture that support scholarship vary greatly from school to school. Yet faculty and student expectations of engaging in such activities have become higher and more evident than ever.

The demand for sharing solutions, identifying opportunities, and strengthening the scholarly environments is growing notably in many business schools. Such research activities depend on there being supportive institutional mechanism, available funds, and eligible expertise. In many cases, collaborative research can also assist faculty development and fulfill their training requirements. A solid research-to-education program would emerge to implement and evaluate the creative and innovative educational materials for advancement in the business field. Faculty often incorporate their collaborative business research findings in classes as supplementary lecture materials. Collaborative business research has provided the opportunity for

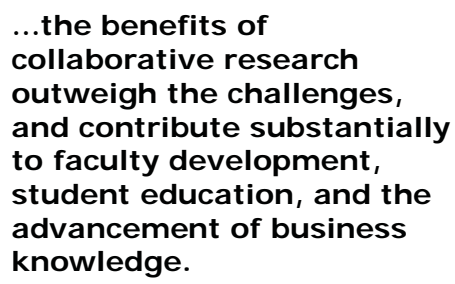

school and business and students to work together. When invited into the project, business managers can reinforce the applications, provide additional viewpoints to the contents, and develop long-term relationships with organizations.

Despite the many substantial benefits of collaboration, some challenges still remain. In some circumstances, business research collaborations are not attested to co-authored papers, and the interactions between partners are too insignificant to result in coauthored publications. Occasionally, additional funding may be needed in collaborative research when interschool, interregional, and international researchers are involved. The demand for additional time may often occur during the collaboration. Sometimes, researchers may need time and patience to resolve the differences in their collaborative project. Challenges might arise because of divergent views, priorities, methods, reward, and promotion issues, and

InSight: A J ournal of Scholarly Teaching 
arbitration may be required to resolve the differences. Collaboration may entail certain unexpected costs: There may be a need for additional administrative procedures, the resolution of cultural differences, and distinctive applications during the phrases of collaboration. However, the benefits of collaborative research outweigh the challenges, and contribute substantially to faculty development, student education, and the advancement of business knowledge.

\section{References}

Adam, S., Hadlock, C., Houghton, D., \& Sirbu, G. (2006), A Recipe for Collaborative Research, BizEd, September/October.

Bartkus, K., Olsen, D., Mills, R., \& Barlow Hills, S. Utah State University (2010), Collaborative Research in Business Schools: Benefits from the Research Group Model, Council on Undergraduate Research, fall, Volume 31, Number.

Bartkus, K., Mills, R., \& Olsen, D. (2010), Fostering Undergraduate Research Experiences in Management Information Systems Through the "Research Group" Framework, American Journal of Business Education, Volume 3, Number 6.

Bayh-Dole Act - Public Law 96-517 (1980), An Act to Amend the Patent and Trademark Laws, $96^{\text {th }}$ Congress, 94 STAT. 3015, December 12.

Fishbaugh, M. S. E. (1997), Models of collaboration. Needham Heights, MA: Allyn \& Bacon.

Katz, J. S. \& Martin, B. R. (1995), What Is Research Collaboration? Science Policy and Research Evaluation Group, ESRC Centre for Science, Technology, Energy and Environment Policy Science Policy Research Unit, University of Sussex, Falmer, Brighton, UK, March.
Keeble, D. \& Lawson, C. (1998), Collective Learning Processes, Networking and 'Institutional Thickness' in the Cambridge Region, ESRC Centre for Business Research, University of Cambridge, Department of Applied Economics, United Kingdom. Paper presented at the 38th Congress of the European Regional Science Association, Vienna, September.

Loan-Clarke, J. \& Preston, D. (2002) 'Tensions and benefits in collaborative research involving a university and another organization', Studies in Higher Education, Vol. 27, No. 2, pp.169-185.

Lopatto, D. (2006), Undergraduate Research as a Catalyst for Liberal Learning. Peer Review, Vol. 22, No. 1, pp:22-26.

National Academy of Sciences (1999), Overcoming Barriers to Collaborative Research, GovernmentUniversity-Industry Research Roundtable sponsored by the National Academy of Sciences, National Academy of Engineering, and the Institute of Medicine, ISBN 0-309-17245-4.

Strand, K., Marullo, S., Cutfoth, Stoecker, R., \& Donohue, P. (2003), Community-Based Research and Higher Education-Principles and Practices, Jossey-Bass: A Wiley Imprint, San Francisco, CA. 
Robert Kao, PhD, is assistant professor of finance in the School of Business at Park University. His research has focused on investment analysis, financial derivatives and markets, resource economics, and quantitative methods. He is currently teaching undergraduate and MBA graduate programs in finance and economics. He is also serving as a finance program coordinator and on advisory councils in the Graduate School and the Center for Excellence in Teaching and Learning at Park University.

InSight: A J ournal of Scholarly Teaching 